\title{
Engineered Antibody Fragments with Infinite Affinity as Reporter Genes for PET Imaging
}

Liu H. Wei ${ }^{1}$, Tove Olafsen ${ }^{1}$, Caius Radu${ }^{1}$, Isabel J. Hildebrandt ${ }^{1}$, Mark R. McCoy ${ }^{2}$, Michael E. Phelps ${ }^{1}$, Claude Meares ${ }^{2}$, Anna M. Wu ${ }^{1}$, Johannes Czernin ${ }^{1}$, and Wolfgang A. Weber ${ }^{1,3}$

\begin{abstract}
${ }^{I}$ Department of Molecular and Medical Pharmacology, David Geffen School of Medicine, University of California, Los Angeles, California; ${ }^{2}$ Department of Chemistry, University of California, Davis, California; and ${ }^{3}$ Department of Nuclear Medicine, University of Freiburg, Freiburg, Germany
\end{abstract}

Reporter gene imaging has great potential for many clinical applications including the tracking of transplanted cells and monitoring of gene therapy. However, currently available reporter genereporter probe combinations have significant limitations with the biodistribution of the reporter probe and the specificity and immunogenicity of the reporter gene. The objective of the present study was to evaluate a new approach for reporter gene imaging based on cell surface expression of antibody fragments that can irreversibly bind to radiometal chelates. Methods: We developed a new reporter gene, designated 1,4,7,10-tetraazacyclodocecane$N, N^{\prime}, N^{\prime \prime}, N^{\prime \prime \prime}$-tetraacetic acid (DOTA) antibody reporter 1 (DAbR1), which consists of the single-chain Fv (scFv) fragment of the antiY-DOTA antibody 2D12.5/G54C fused to the human T cell CD4 transmembrane domain. The corresponding reporter probe is yttrium-(S)-2-(4-acrylamidobenzyl)-DOTA (*Y-AABD), a DOTA complex that binds irreversibly to a cysteine residue in the 2D12.5/G54C antibody. U-87 glioma cells were stably transfected with a DAbR1 expression vector. Binding of * $Y-A A B D$ to transfected and wild-type cells was studied in vitro and in vivo. Results: Flow cytometry revealed high expression of the DAbR1 protein on the cell surface of tumor cells. Uptake of 90Y-AABD in DAbR1-expressing human U-87 glioma xenografts was $6.2( \pm 1.3)$ percentage injected dose per gram $(\% \mathrm{ID} / \mathrm{g})$ at $1 \mathrm{~h}$ and $4.9( \pm 0.62) \% \mathrm{ID} / \mathrm{g}$ at $24 \mathrm{~h}$ after injection. The corresponding tumor-to-plasma ratios were $45: 1$ and 428:1, respectively. Uptake by U-87 tumors without the DAbR1 gene was $0.16( \pm 0.02)$ $\% \mathrm{ID} / \mathrm{g}$ at $1 \mathrm{~h}$ and $0.05( \pm 0.03) \% \mathrm{ID} / \mathrm{g}$ at $24 \mathrm{~h}$. PET images in mice with ${ }^{86}$ Y-AABD demonstrated intense uptake in DAbR1positive tumors and low background activity in the liver. Conclusion: These findings indicate that cell surface expression of radiometal chelate binding antibodies such as 2D12.5/G54C is a promising strategy for reporter gene imaging.

Key Words: reporter gene; noninvasive imaging; single-chain Fv antibody; surface expression; AABD

J Nucl Med 2008; 49:1828-1835

DOI: 10.2967/jnumed.108.054452

\footnotetext{
Received May 20, 2008; revision accepted Aug. 11, 2008.

For correspondence or reprints contact: Wolfgang A. Weber, Department of Nuclear Medicine, University of Freiburg, Hugstetterstrasse 55, 79105 Freiburg, Germany.

E-mail: wolfgang.weber@uniklinik-freiburg.de

Guest Editor: Uwe Haberkorn, University of Heidelberg

COPYRIGHT @ 2008 by the Society of Nuclear Medicine, Inc.
}

$\mathbf{T}$ ransplantation of genetically engineered cells is a field of intense research in almost all areas of medicine and may lead to the treatment of a large number of common diseases. Prominent examples include transplantation of stem cells after myocardial infarction $(1,2)$, adoptive cell immunotherapy of melanoma and other malignant diseases (3), islet cell transplantation in insulin-dependent diabetes (4), and treatment of Parkinson disease and other neurodegenerative disorders with neuronal cells $(5,6)$. Imaging techniques are valuable to these diverse applications, to study noninvasively and quantitatively the location, viability, and function of the transplanted cells in animal models and patients. Such techniques have to be both highly sensitive and highly specific, because small amounts of transplanted cells need to be identified and the signal from the much larger number of host cells should not interfere with the imaging of the transplanted cells.

Currently, reporter gene imaging with PET appears best suited to meet these stringent requirements. PET imaging of reporter genes involves the administration of a probe that is selectively bound or metabolized via interaction with the gene product in the reporter gene-transduced cells. Herpes simplex virus type 1 thymidine kinase (HSV1-tk) and its mutant HSV1-sr39tk are the most widely used reporter genes for PET and have been intensively studied for the monitoring of cancer gene therapy (7-9). The corresponding reporter probes are ${ }^{124}$ I-fluoro-deoxy-arabinofuranosyl-5-iodouracil ( $\left.{ }^{124} \mathrm{I}-\mathrm{FIAU}\right),{ }^{18} \mathrm{~F}$-fluoro-hydroxymethybutyl-guanine $\left({ }^{18} \mathrm{~F}-\right.$ FHBG), and ${ }^{18} \mathrm{~F}-2$ '-fluoro- 2 '-deoxy-1- $\beta$-D- $\beta$-arabinofuranosyl5-ethyluracil ( ${ }^{18} \mathrm{~F}$-FEAU). Because HSV1-tk is a viral protein, immune reactions are a serious concern for the use of this reporter gene for imaging of stem cells or other cells that are intended to survive for longer periods after transplantation. Indeed, immune responses specific to the HSV-tk protein were reported in 5 of 6 patients who received anti-HIV cytotoxic HSV1-tk-transduced T lymphocytes, and the transduced $\mathrm{T}$ cells were eliminated (10). Furthermore, currently available reporter probes for HSV1-tk or HSV1-sr39tk are, to a small extent, also phosphorylated by mammalian thymidine kinases. Thus, rapidly proliferating 
mammalian cells, such as cancer cells, show some uptake of these reporter probes. This nonspecific signal has been shown to limit the detection of lymphocytes expressing HSV1-sr39tk within the tumor tissue (11).

Several other reporter gene combinations have been evaluated. These include the sodium iodide symporter (NIS) $(12,13)$, the norepinephrine transporter (NET) $(14,15)$, and somatostatin (16) and dopamine $\mathrm{D}_{2}$ receptors (17). Although these mammalian proteins avoid the problem of immunogenicity, their physiologic expression pattern limits the organ systems that can be studied with these reporter genes. Furthermore, currently available reporter probes for these reporter genes have unfavorable biologic (high hepatobiliary clearance) or physical properties (low branching ratio and long physical half-life of the radiolabel) for PET.

To overcome these limitations, we explored the feasibility of using cell surface-bound antibody fragments as reporter genes that can bind covalently to small haptens such as radiometal chelates, which act as reporter probes (Fig. 1A). Two earlier studies $(18,19)$ have used related strategies, but without irreversible capture of the probe by the antibody. In general, the antibody-probe approach has 3 advantages, compared with other reporter gene-reporter probe combinations. First, the pharmacokinetics of the reporter probe can easily be optimized. Haptens can be designed to exhibit rapid blood clearance and low nonspecific binding to normal tissues. Once a hapten demonstrates favorable properties for imaging, an antibody can be raised against this hapten and used as a reporter gene. With the current reporter gene-

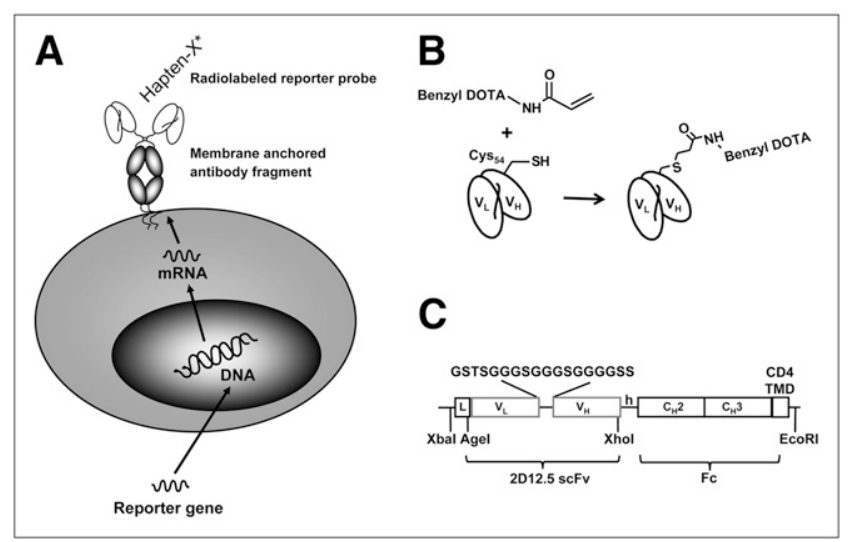

FIGURE 1. (A) Use of antibody fragments as reporter genes. Cells are transfected with gene-encoding antibody fragment with membrane-anchoring domain. Antibody fragment is expressed on cell surface and acts as artificial receptor for binding small radiolabeled haptens. (B) Irreversible binding of AABD to 2D12.5/G54C. Covalent bond is formed between cysteine 54 in variable heavy chain of antibody and acryl group of AABD. (C) Schematic presentation of DAbR1 fusion gene. DAbR1 reporter gene consists of scFv fragment of 2D12.5/G54C fused to human Fc $(\mathrm{CH} 2-\mathrm{CH} 3)$ fragment and human T cell CD4 transmembrane domain, which anchors DAbR1 in plasma membrane. $\mathrm{V}_{\mathrm{H}}=$ variable heavy; $\mathrm{V}_{\mathrm{L}}=$ variable light. reporter probe combinations, optimization of the pharmacokinetic properties of the reporter probe is limited because any modifications can also affect target binding. As a consequence, it is difficult to optimize both target binding and pharmacokinetic properties, and the number of available reporter gene-reporter probe combinations has remained limited despite intensive research. Second, antibodies can provide an extremely high specificity for reporter probes. Furthermore, the reporter probes can be purely synthetic molecules with no natural analogs, making it straightforward to avoid problems such as modification by naturally occurring enzymes or competition for target binding by endogenous molecules. Also, the antibody can be engineered to bind the reporter probe irreversibly (with infinite affinity), so that the signal persists in the target while the probe clears from normal tissues, whereas antibody complexes with small molecules may dissociate too quickly for optimal results (20). In developing an infinite affinity system, it is essential that the reporter probe clears from the subject without nonspecific attachment to normal proteins. We accomplished this by incorporating a mild acryloyl group into the reporter probe, which reacts efficiently in the engineered antibody binding site but has low reactivity with blood components (21). Finally, the number of antibodies that can be used as reporter genes is virtually unlimited. In contrast, only a limited number of suitable viral or mammalian reporter genes exists. Cross-reactivity must be considered because, for example, the antibody used here can bind irreversibly to $1,4,7,10$-tetraazacyclodocecane- $N, N^{\prime}, N^{\prime \prime}, N^{\prime \prime \prime}$-tetraacetic acid (DOTA) complexes containing any of the lanthanide elements (22), but synthetic chemistry can easily meet this challenge by preparing nonbinding analogs. Therefore, antibody-based reporter genes are better suited for the multiplexed imaging of the expression of several genes.

To demonstrate the feasibility of antibody-based reporter genes, we have used the engineered antibody 2D12.5/G54C as a reporter gene and yttrium-(S)-2-(4-acrylamidobenzyl)DOTA (*Y-AABD) as a reporter probe. The 2D12.5/G54C antibody binds yttrium-DOTA and also other rare earthDOTA metal complexes. Binding of *Y-AABD to 2D12.5/ G54C brings the acryloyl group of AABD near an engineered cysteine side chain at position 54 of the heavy chain of the antibody (Fig. 1B), which results in covalent binding of AABD via a Michael reaction (22). To achieve cell surface expression of 2D12.5/G54C, we fused the single-chain $\mathrm{Fv}$ fragment (scFv) of 2D12.5/G54C with a human immunoglobulin Fc region and the CD4 transmembrane domain. The resulting protein DOTA antibody reporter 1 (DAbR1) was expressed in the human glioblastoma cell line U-87. Cell culture and biodistribution studies and small-animal PET imaging of tumor-bearing mice demonstrated high and specific binding of *Y-AABD to tumor cells expressing DAbR1. These data indicate that antibody-based reporter genes that irreversibly capture probe molecules represent a promising new platform for the development of new reporter probe-reporter gene combinations. 


\section{MATERIALS AND METHODS}

\section{Design and Gene Assembly of 2D12.5/G54C scFv-Fc-} CD4 Construct (DAbR1 Gene)

The variable light and heavy genes from the murine 2D12.5 monoclonal antibody containing the G54C mutation (22) were amplified and assembled into $\mathrm{scFv}$ by polymerase chain reaction (PCR). In separate PCRs, genes encoding human IgG4 Fc (hinge$\mathrm{C}_{\mathrm{H}} 2-\mathrm{C}_{\mathrm{H}} 3$; gift from Dr. Mirela Claude Jensen) and CD4 transmembrane domain and truncated intracellular domain of the CD3 complex $\zeta$-chain (23) were amplified and assembled into 1 gene ( $\mathrm{Fc}-\mathrm{CD} 4)$. The final $2 \mathrm{PCR}$ products were assembled in $\mathrm{pUC}$ (New England Biolabs) already containing a $5^{\prime}$ leader peptide sequence using the restriction enzyme sites shown in Figure 1C. The complete complementary DNA construct encoding the leader and $\mathrm{scFv}-\mathrm{Fc}-\mathrm{CD} 4$ was transferred using $\mathrm{Xba \textrm {I }}$ and $E c o \mathrm{RI}$ sites into the mammalian expression vector pcDNA3.1 (-) under the control of the cytomegalovirus promoter (Invitrogen).

\section{Cell Line, Culture Conditions, and Transfection Procedure}

The U-87 human glioma cell line, obtained from American Type Culture Collection, was maintained at $37^{\circ} \mathrm{C}$ in complete Dulbecco's modified Eagle's medium containing 10\% (v/v) fetal bovine serum. The DAbR1-pcDNA vector was transfected into U-87 cells by electroporation (Amaxa) according to the manufacturer's instructions. Stably transfected cells were selected with the antibiotic G418 (500 $\mu \mathrm{g} / \mathrm{mL}$; Invitrogen) in complete Dulbecco's modified Eagle's medium. After about 3 wk, G418-resistant clones were isolated and analyzed individually for the expression of human Fc by Western blots and flow cytometry (fluorescenceactivated cell sorter [FACS]). These experiments were performed when the cell density was about 10 million cells/ $75-\mathrm{cm}^{2}$ tissue culture flask.

\section{Western Blot Analysis}

Samples (20 $\mu \mathrm{g}$ of total proteins from whole-cell lysates) were subjected to sodium dodecyl sulfate-polyacrylamide gel electrophoresis $(10 \%)$ and transferred to a nitrocellulose membrane. After $1 \mathrm{~h}$ at room temperature in blocking buffer (Licor Bioscience), the membranes were probed with rabbit antihuman $\mathrm{Fc}$ fragment (1:1,000; Jackson ImmunoResearch Lab). The membranes were washed with phosphate-buffered saline (PBS) with polysorbate 20 and incubated with IRDye 800-conjugated goat antirabbit antibody (infrared dye, 1:10,000; Licor Bioscience). Membranes were washed 4 times with Tris-buffered saline with polysorbate (TBST), and then rinsed with PBS before being scanned using an Odyssey infrared imaging system according to the manufacturer's instructions (Licor Bioscience).

\section{Flow Cytometry}

Either DAbR1-expressing or wild-type U-87 cells $\left(1 \times 10^{6}\right)$ were incubated with rabbit antihuman $\mathrm{IgG}$ antibody (Fc-specific) for 20 min in PBS containing 1\% fetal bovine serum (FACS buffer). Cells were washed twice with formaldehyde buffer and incubated with Alexa Fluor 488-conjugated goat antirabbit IgG (Invitrogen). After 2 washes, cells were analyzed by a FACScan flow cytometer (Becton Dickinson) using the CellQuest 3.1 software for acquisition and the ModFit LT 2.0 software (Verity) for analysis.

\section{Preparation of ${ }^{90} \mathrm{Y}-\mathrm{AABD}$ and ${ }^{86} \mathrm{Y}$-AABD}

The bifunctional chelating agent AABD was prepared following the method of Corneillie et al. (24) ${ }^{90} \mathrm{Y}$ in $0.05 \mathrm{M}$ hydrochloric acid (specific activity, $18.5 \mathrm{TBq} / \mathrm{mg}$ ) was purchased from PerkinElmer, and ${ }^{86} \mathrm{Y}$ in $0.1 \mathrm{M}$ hydrochloric acid (specific activity, $1 \mathrm{TBq} / \mathrm{mg}$ ) was purchased from Isotrace Technologies (25). A total of $37 \mathrm{MBq}$ $(1 \mathrm{mCi})$ of ${ }^{90} \mathrm{Y}$ or ${ }^{86} \mathrm{Y}$ was incubated at $37^{\circ} \mathrm{C}$ for $1 \mathrm{~h}$ with $1.2 \mathrm{mM}$ AABD in $0.5 \mathrm{M}$ triethylammonium acetate buffer $(\mathrm{pH}, 5.5)$. At the end of incubation, diethylenetriamine pentaacetate (DTPA) was added to the final concentration of $10 \mathrm{mM}$ and incubated at room temperature for $5 \mathrm{~min}$ to scavenge any unchelated ${ }^{90} \mathrm{Y}$ or ${ }^{86} \mathrm{Y}$.

\section{In Vitro Antibody Binding Assay}

One million DAbR1-expressing and wild-type U-87 cells were plated in 6-well plates in triplicate the day before the experiment. On the day of the experiment, cells were incubated with $37 \mathrm{kBq}(1 \mu \mathrm{Ci})$ of ${ }^{90} \mathrm{Y}-\mathrm{AABD}$ in $1 \mathrm{~mL}$ of RPMI medium containing $0.5 \%$ fetal bovine serum, with rocking at room temperature for $2 \mathrm{~h}$. The cells were then washed twice with cold PBS and lysed with $0.1 \%$ sodium dodecyl sulfate. The lysates were transferred to scintillation liquid and counted in a $\beta$-counter (5600; Packard) to determine the amount of radioactivity bound to the cells. Duplicate 6-well plates without radioactivity were used to determine the number of cells per well.

\section{Xenograft Models}

Severe combined immunodeficient mice were purchased from the Jackson Laboratory. All animal manipulations were conducted with sterile techniques using the guidelines of the UCLA Animal Research Committee. Wild-type and DAbR1-expressing U-87 cells were used to generate xenografts in mice. Cells growing exponentially in culture were suspended in 50\% PBS and 50\% Matrigel (BD Biosciences) and injected subcutaneously at the right shoulder (1-3 $\times 10^{6}$ cells/mouse). To evaluate whether the accumulation of ${ }^{90}$ Y-AABD correlated with DAbR1 expression levels, DAbR1expressing U-87 cells were diluted with wild-type U-87 cells to obtain a mixed population containing $0 \%, 10 \%, 25 \%, 50 \%$, and $100 \%$ of DAbR1-expressing cells. Animals were used for biodistribution studies or underwent small-animal PET/CT scans after tumor volumes had reached $50-100 \mathrm{~mm}^{3}$ (1-3 wk after injection).

\section{Biodistribution Studies in Tumor-Bearing Animals}

Mice bearing U-87 wild-type or U-87-DAbR1 xenografts were injected via the tail vein with $1,480 \mathrm{kBq}(40 \mu \mathrm{Ci})$ of ${ }^{90} \mathrm{Y}-\mathrm{AABD}$ in $100 \mu \mathrm{L}$ of saline. Groups of 3 mice each were sacrificed at 1 and $24 \mathrm{~h}$ after injection of ${ }^{90} \mathrm{Y}-\mathrm{AABD}$. Blood, organs, and tumors were removed and weighed, and the amount of radioactivity was determined using a $\beta$-counter (5600; Packard). Radioactivity determinations were normalized by the weight of the tissue and amount of radioactivity injected to obtain the percentage injected dose per gram $(\% \mathrm{ID} / \mathrm{g})$ of tissue.

\section{Small-Animal PET/CT Imaging}

Small-animal PET/CT scans were performed using the microPET FOCUS 220 (26) (Siemens Preclinical Solutions) and MicroCAT II scanners (Siemens Preclinical Solutions). For PET/CT, mice were anesthetized using $1.5 \%-2 \%$ isoflurane and positioned in a plastic imaging chamber that minimized positioning errors between PET and CT (27). After an injection of ${ }^{86}$ Y-AABD (3,700 kBq [100 $\mu \mathrm{Ci}]$ ) via a tail vein catheter, a 1-h dynamic PET scan was acquired. Fourteen hours after injection, the same mice underwent a second, 10-min static scan. Images were reconstructed by filtered backprojection, using a ramp filter with a cutoff frequency of 0.5 Nyquist. Image counts per pixel per second were calibrated to activity concentrations $(\mathrm{Bq} / \mathrm{mL})$ by measuring a $3.5-\mathrm{cm}$ cylinder phantom filled with a known concentration of ${ }^{86} \mathrm{Y}$. Immediately after each 
PET scan, mice underwent a 7-min micro-CT scan, using routine image acquisition parameters (27). For quantification, activity concentrations were expressed as percentage of the decay-corrected injected activity per gram of tissue by using the AMIDE software (28). Spheric regions of interest were drawn around the tumor and various normal organs. Regions of interest were defined on fused PET/CT images generated by the AMIDE software to ensure accurate anatomic positioning.

\section{Statistical Analysis}

Results were expressed as mean $\pm 1 \mathrm{SD}$. Statistical comparisons were made by 2 -tailed $t$ tests or ANOVA as appropriate. Linear regression analysis was used to study the association between quantitative parameters. A $P$ value of less than 0.05 was considered statistically significant.

\section{RESULTS}

\section{Expression of DAbR1 in Human U-87 Glioma Cells and In} Vitro Binding of ${ }^{90} \mathrm{Y}-\mathrm{AABD}$

Expression of the DAbR1 protein by transfected U-87 clones was confirmed by Western blots (Fig. 2A). Next, we evaluated whether the DAbR1 protein traffics to the cell surface. FACS analysis (performed on nonpermeabilized cells) demonstrated binding of the anti-Fc antibody to U-87DAbR1 cells but not to U-87 wild-type cells (Figs. 2B and 2C). Because the anti-Fc antibody cannot cross the cell membrane, specific binding to U-87-DAbR1 cells proves cell surface expression of DAbR1.

After $2 \mathrm{~h}$ of incubation with ${ }^{90} \mathrm{Y}-\mathrm{AABD}$, the binding by U-87-DAbR1 cells was 24,484 ( \pm 158$) \mathrm{cpm} / \mathrm{million}$ cells, whereas it was only $253( \pm 1.4) \mathrm{cpm} /$ million cells for U-87

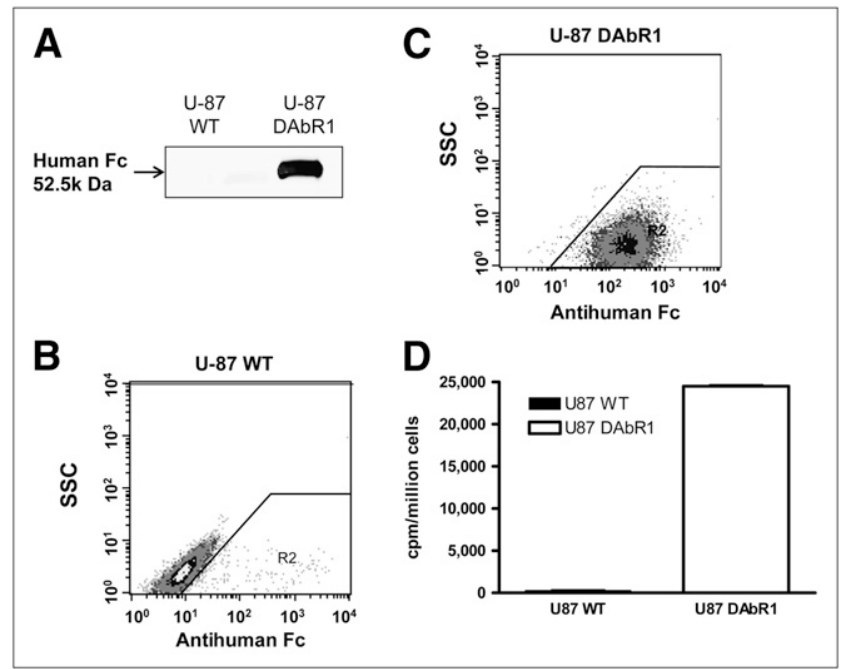

FIGURE 2. (A) Western blots of wild-type and DAbR1expressing U-87 cell lysates using antihuman Fc antibody for detection. FACS analyses of wild-type (B) and DAbR1expressing $\mathrm{U}-87(\mathrm{C})$ cells with antihuman $\mathrm{Fc}$ antibody. $x$-axis shows fluorescence due to antihuman Fc antibody binding, and $y$-axis shows side scatter; both are in arbitrary units, as common in flow cytometry. (D) In vitro binding of ${ }^{90} \mathrm{Y}-\mathrm{AABD}$ to wild-type and DAbR1-expressing U-87 cells. $\mathrm{cpm}=$ counts per minute; SSC = side scatter; WT = wild type. wild-type cells. Thus, transfection with DAbR1 led to an almost 100-fold increase (ratio, 96.8) in the binding of the reporter probe ${ }^{90} \mathrm{Y}-\mathrm{AABD}$ (Fig. 2C). The U-87-DAbR1 cells expressed membrane-bound DAbR1 protein that was able to specifically bind high amounts of the reporter probe ${ }^{90} \mathrm{Y}-\mathrm{AABD}$ in vitro.

\section{Biodistribution of ${ }^{90} \mathrm{Y}-\mathrm{AABD}$ in Tumor-Bearing Mice}

At $1 \mathrm{~h}$ after injection, tumor binding of ${ }^{90} \mathrm{Y}-\mathrm{AABD}$ in DAbR1-positive tumors was $6.23( \pm 1.32) \% \mathrm{ID} / \mathrm{g}$, and the tumor-to-plasma ratio was 45:1. At $24 \mathrm{~h}$ after injection, the binding of ${ }^{90} \mathrm{Y}$-AABD in DAbR1-positive tumors was 4.89 $( \pm 0.62) \% \mathrm{ID} / \mathrm{g}$, with a tumor-to-plasma ratio of $428: 1$ (Tables 1 and 2). At both time points, tumor uptake of ${ }^{90} \mathrm{Y}-$ AABD was significantly higher than that of all other sampled tissues $(P<0.05)$. Uptake of ${ }^{90}$ Y-AABD in U-87 wild-type tumors was $0.16( \pm 0.02) \% \mathrm{ID} / \mathrm{g}$ at $1 \mathrm{~h}$ after injection, which decreased to $0.05( \pm 0.03) \% \mathrm{ID} / \mathrm{g}$ at $24 \mathrm{~h}$ after injection (Table 1). Thus, the uptake of ${ }^{90} \mathrm{Y}-\mathrm{AABD}$ by U-87-DAbR1 was 39-fold and 100-fold higher than that of the wild-type tumors at 1 and $24 \mathrm{~h}$ after injection, respectively $(P<0.001)$. Table 1 summarizes the uptake of ${ }^{90}$ Y-AABD in the various tissues sampled at 1 and $24 \mathrm{~h}$ after injection. Table 2 shows the corresponding tumor-to-organ ratios. Of all normal tissues sampled, the liver showed the highest radioactivity uptake, with approximately $3 \% \mathrm{ID} / \mathrm{g}$ at $1 \mathrm{~h}$ after injection and $0.9 \% \mathrm{ID} / \mathrm{g}$ at $24 \mathrm{~h}$. For DAbR1 tumors, the tumor-to-liver ratios at 1 and $24 \mathrm{~h}$ after injection were 2.36 ( \pm 0.44$)$ and 6.30 $( \pm 1.32)$, respectively. The tumor-to-kidney ratios were 7.67 $( \pm 2.30)$ at $1 \mathrm{~h}$ after injection and $33.46( \pm 6.12)$ at $24 \mathrm{~h}$ after injection. The excreted radioactivity, which might contain metabolic products of $*$ Y-AABD, was not investigated further. In mice injected with mixtures of U-87 wild-type and U-87-DAbR 1 cells, the accumulation of ${ }^{90}$ Y-AABD at $24 \mathrm{~h}$ after injection correlated with the number of DAbR1-positive U-87 cells ( $r=0.89, P<0.001$ for linear fit; Fig. 3 ).

\section{Imaging of DAbR1-Positive U-87 Tumors with High Contrast by Small-Animal PET}

Figure 4A shows a series of dynamic images (coronal sections) from 1 to $60 \mathrm{~min}$ after injection in a mouse carrying a U-87-DAbR1 xenograft. Images demonstrate ${ }^{86}$ Y-AABD accumulation in the tumor and rapid renal and hepatobiliary clearance of ${ }^{86}$ Y-AABD. Corresponding time-activity curves for tumor tissue, skeletal muscle, and liver are shown in Figure 4B (average of 3 scans). At $1 \mathrm{~h}$ after injection, the radioactivity uptake for DAbR1 tumors was $7.7( \pm 0.9) \% \mathrm{ID} / \mathrm{g}$, liver uptake was $3.1( \pm 1.5) \% \mathrm{ID} / \mathrm{g}$, and muscle activity was 0.3 ( \pm 0.4$) \% \mathrm{ID} / \mathrm{g}$. U-87 wild-type xenograft tumors showed background activity levels at $1 \mathrm{~h}$ after injection $(0.28[ \pm 0.2]$ $\%$ ID/g) with ${ }^{86}$ Y-AABD. In PET scans acquired at $14 \mathrm{~h}$ after injection, the U-87-DAbR1 tumors demonstrated intense focal tracer uptake, whereas radioactivity had cleared from the kidneys, liver, and gastrointestinal tract (Fig. 5A). In wild-type tumors, no radioactivity uptake above background was detected (Fig. 5B). Quantitative analysis of tracer uptake at $14 \mathrm{~h}$ after injection (Fig. 5C) demonstrated that radioac- 
TABLE 1

Biodistribution of ${ }^{90} \mathrm{Y}-\mathrm{AABD}(n=3)$

\begin{tabular}{|c|c|c|c|c|c|c|c|c|}
\hline \multirow[b]{3}{*}{ Region } & \multicolumn{4}{|c|}{$1 \mathrm{~h}$ after injection } & \multicolumn{4}{|c|}{$24 \mathrm{~h}$ after injection } \\
\hline & \multicolumn{2}{|c|}{$\begin{array}{c}\text { DAbR1-expressing } \\
\text { U-87 group }\end{array}$} & \multicolumn{2}{|c|}{$\begin{array}{l}\text { Wild-type U-87 } \\
\text { group }\end{array}$} & \multicolumn{2}{|c|}{$\begin{array}{c}\text { DAbR1-expressing } \\
\text { U-87 group }\end{array}$} & \multicolumn{2}{|c|}{$\begin{array}{l}\text { Wild-type U-87 } \\
\text { group }\end{array}$} \\
\hline & $\% \mathrm{ID} / \mathrm{g}$ & SD & $\% \mathrm{ID} / \mathrm{g}$ & SD & $\% \mathrm{ID} / \mathrm{g}$ & $\overline{S D}$ & $\% \mathrm{ID} / \mathrm{g}$ & SD \\
\hline Tumor & 6.23 & 1.32 & 0.16 & 0.02 & 4.89 & 0.62 & 0.05 & 0.03 \\
\hline $\mathrm{RBC}$ & 0.03 & 0.01 & 0.02 & 0.01 & 0.00 & 0.00 & 0.01 & 0.01 \\
\hline Plasma & 0.16 & 0.01 & 0.05 & 0.01 & 0.01 & 0.00 & 0.02 & 0.01 \\
\hline Heart & 0.08 & 0.01 & 0.2 & 0.03 & 0.02 & 0.01 & 0.02 & 0.01 \\
\hline Liver & 2.97 & 0.91 & 3.38 & 1.51 & 0.79 & 0.33 & 1.08 & 0.54 \\
\hline Brain & 0.10 & 0.12 & 0.02 & 0.00 & 0.01 & 0.00 & 0.06 & 0.08 \\
\hline Stomach & 0.32 & 0.01 & 0.66 & 0.13 & 0.04 & 0.02 & 0.31 & 0.42 \\
\hline Small intestine & 1.61 & 1.26 & 0.87 & 0.21 & 0.26 & 0.35 & 0.02 & 0.00 \\
\hline Colon & 1.32 & 0.37 & 2.48 & 1.79 & 0.03 & 0.01 & 0.07 & 0.01 \\
\hline Spleen & 0.69 & 0.51 & 0.96 & 0.61 & 1.30 & 0.47 & 0.45 & 0.19 \\
\hline Kidney & 0.83 & 0.01 & 1.67 & 1.09 & 0.14 & 0.05 & 0.14 & 0.11 \\
\hline Skeletal muscle & 0.50 & 0.35 & 0.07 & 0.01 & 0.01 & 0.00 & 0.02 & 0.02 \\
\hline Skin & 0.38 & 0.38 & 0.31 & 0.24 & 0.02 & 0.00 & 0.07 & 0.05 \\
\hline Femur & 0.57 & 0.56 & 0.18 & 0.15 & 0.19 & 0.13 & 0.18 & 0.16 \\
\hline $\mathrm{RBC}=$ red blooc & & & & & & & & \\
\hline
\end{tabular}

tivity uptake in DAbR1 tumors $(5.2[ \pm 1.7] \% \mathrm{ID} / \mathrm{g})$ was 6.5 times that in the liver $(0.8[ \pm 0.4] \% \mathrm{ID} / \mathrm{g})$, the normal organ with the highest tracer uptake.

\section{DISCUSSION}

The present study indicates that antibody fragments that capture radiometal chelates are likely to be successful in the form of reporter genes for PET. Cell surface expression of an scFv fragment of the anti-DOTA antibody 2D12.5/G54C resulted in high, specific, persistent uptake of the reporter probe *Y-AABD. *Y-AABD was retained in the tumor tissue for $24 \mathrm{~h}$, whereas it rapidly cleared from all normal organs, resulting in excellent tumor-to-background ratios and high-contrast PET images. In vivo binding of *Y-AABD by wild-type tumors was about 100 times lower than that of DAbR1-positive tumors and not different from background activity.

Biodistribution and tumor uptake of *Y-AABD compare favorably with data in the literature on other reporter genereporter probe combinations. Tumor uptake of $*$ Y-AABD in tumors expressing DAbR1 appears to be at least as high as that reported for FHBG/HSV1-sr39tk, FIAU/HSV1-tk, and

TABLE 2

Tumor-to-Blood and Tumor-to-Organ Ratios

\begin{tabular}{|c|c|c|c|c|c|c|c|c|}
\hline \multirow[b]{3}{*}{ Region } & \multicolumn{4}{|c|}{$1 \mathrm{~h}$ after injection } & \multicolumn{4}{|c|}{$24 \mathrm{~h}$ after injection } \\
\hline & \multicolumn{2}{|c|}{$\begin{array}{c}\text { DAbR1-expressing } \\
\text { U-87 tumors }\end{array}$} & \multicolumn{2}{|c|}{$\begin{array}{c}\text { Wild-type U-87 } \\
\text { tumors }\end{array}$} & \multicolumn{2}{|c|}{$\begin{array}{c}\text { DAbR1-expressing } \\
\text { U-87 tumors }\end{array}$} & \multicolumn{2}{|c|}{$\begin{array}{l}\text { Wild-type U-87 } \\
\text { tumors }\end{array}$} \\
\hline & Ratio & SD & Ratio & $\mathrm{SD}$ & Ratio & SD & Ratio & SD \\
\hline $\mathrm{RBC}$ & 267.17 & 128.46 & 9.59 & 5.56 & 2074.67 & 834.86 & 14.26 & 7.17 \\
\hline Plasma & 45.02 & 12.76 & 2.34 & 1.57 & 427.60 & 67.07 & 2.97 & 0.36 \\
\hline Heart & 97.88 & 27.47 & 1.04 & 0.42 & 278.09 & 57.61 & 2.70 & 0.17 \\
\hline Liver & 2.36 & 0.44 & 0.05 & 0.02 & 6.30 & 1.32 & 0.06 & 0.03 \\
\hline Brain & 693.69 & 31.54 & 9.82 & 2.31 & 1732.81 & 644.70 & 11.03 & 10.21 \\
\hline Stomach & 30.04 & 18.49 & 0.57 & 0.57 & 116.71 & 31.94 & 1.69 & 0.83 \\
\hline Small intestine & 4.26 & 2.68 & 0.14 & 0.08 & 201.49 & 108.56 & 2.07 & 0.62 \\
\hline Colon & 4.78 & 0.36 & 0.08 & 0.04 & 142.73 & 94.13 & 0.71 & 0.19 \\
\hline Spleen & 9.80 & 5.40 & 0.21 & 0.11 & 4.78 & 1.38 & 0.10 & 0.04 \\
\hline Kidney & 7.67 & 2.30 & 0.13 & 0.05 & 33.46 & 6.12 & 0.35 & 0.04 \\
\hline Skeletal muscle & 17.85 & 5.26 & 2.33 & 0.54 & 415.79 & 50.13 & 6.73 & 4.26 \\
\hline Skin & 72.30 & 10.19 & 0.69 & 0.34 & 203.95 & 91.48 & 1.11 & 0.47 \\
\hline Femur & 34.67 & 10.54 & 1.13 & 1.08 & 44.96 & 6.41 & 0.40 & 0.09 \\
\hline
\end{tabular}

1832 The Journal of Nuclear Medicine • Vol. 49 • No. 11 • November 2008 


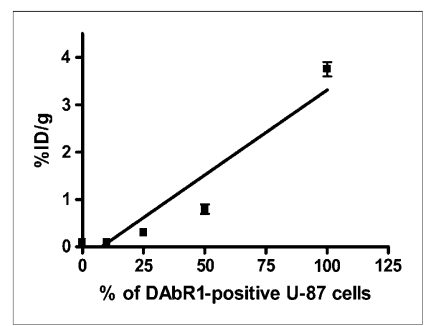

FIGURE 3. ${ }^{90} \mathrm{Y}-\mathrm{AABD}$ accumulation in tumors consisting of mixed populations of DAbR1-positive and -negative U-87 cells. Each data point shows average and SEM for 3 mice. Statistically significant linear relationship between percentage of DAbR1-positive tumor cells and uptake of ${ }^{90} Y$ $\operatorname{AABD}(r=0.89, P<0.001)$ is demonstrated.

NET/metaiodobenzylguanidine (MIBG) $(15,29-31)$ in stably transfected cell lines. Uptake of iodide in tumors transfected with NIS has been shown to be more than $30 \% \mathrm{ID} / \mathrm{g}$ at $1 \mathrm{~h}$ after injection (32); however, this is followed by a rapid washout of radioactivity ( $0.4 \% \mathrm{ID} / \mathrm{g}$ at $24 \mathrm{~h}$ after injection). The specificity of tracer uptake (ratio of tracer uptake by transfected vs. wild-type tumors) for *Y-AABD was almost 100 in our study. This is higher than the published literature data for FHBG (reported ratio, 11) (31) and FIAU (reported ratio, 65) (33). For NET/MIBG and NIS/iodide, ratios of 33 and 31 have been reported $(15,32)$.

In addition to high and specific tumor uptake, *Y-AABD demonstrated a favorable biodistribution in mice bearing DAbR 1-expressing tumors. Already at $1 \mathrm{~h}$ after injection, all tumor-to-organ ratios were greater than 2 , and that was further improved at $24 \mathrm{~h}$ after injection (Table 2). Tumor-tomuscle and tumor-to-plasma ratios were more than 400 at $24 \mathrm{~h}$, and the tumor-to-liver ratio was improved to 6 (Table 2). These tumor-to-organ ratios are higher than the ratios reported for FHBG, FIAU, MIBG, and radioiodine as reporter probes in stably transfected cells. For example, in rat glioma xenografts, the tumor-to-muscle and tumor-toplasma ratios for FHBG at $24 \mathrm{~h}$ after injection were 124 and 25 , respectively (33). The corresponding ratios for FHBG,
MIBG, and radioiodine are on the same order or lower $(15,32-35)$.

When comparing biodistribution and tumor uptake of other reporter gene-probe combinations with that of DAbR1*Y-AABD found in this study, one needs to consider that different tumor cell lines, different modes of transfection, and different mouse strains were used. In addition, data were not normalized to the amount of protein or RNA synthesized by the transfected cells. Nevertheless, the high tumor-toorgan ratios obtained with DAbR1 and *Y-AABD relative to other reporter gene-reporter probe combinations indicates that DAbR1 and *Y-AABD represent a promising reporter gene-reporter probe combination.

Northrop et al. (18) have studied an anti-fluorescein isothiocyanate (FITC) scFv antibody fragment as a reporter gene for $\gamma$-camera imaging using ${ }^{111}$ In-DTPA-FITC as a reporter probe. However, ${ }^{111}$ In-DTPA-FITC demonstrated high kidney uptake and the tumor-to-kidney uptake ratio was less than 1 in this study (18). The maximum tumor uptake was $2.8 \% \mathrm{ID} / \mathrm{g}$, and the ratio of tumor uptake by cells expressing the anti-FITC antibody fragment and wild-type tumors was about 8 . Thus, ${ }^{111}$ In-DTPA-FITC demonstrated a less favorable biodistribution, lower tumor uptake, and less specific tumor uptake than did the *Y-AABD used in our study. More recently, Roffler et al. (19) used an antidansyl (DNS) antibody as a reporter gene and the bivalent ligand $\mathrm{DNS}_{2}-{ }^{111} \mathrm{In}$ DTPA as a reporter probe. At $48 \mathrm{~h}$ after injection, the radioactivity in anti-DNS-expressing tumors was about 2 $\% \mathrm{ID} / \mathrm{g}$ and 15 times higher than that of tumors transfected with a control gene. The tumor-to-blood, tumor-to-kidney, and tumor-to-liver ratios were approximately 72,6 , and 8 , respectively (19). Imaging at earlier time points yielded less favorable tumor-to-organ ratios. When these results are compared with our data, the specificity of tumor uptake and the biodistribution in the *Y-AABD and DAbR1 system

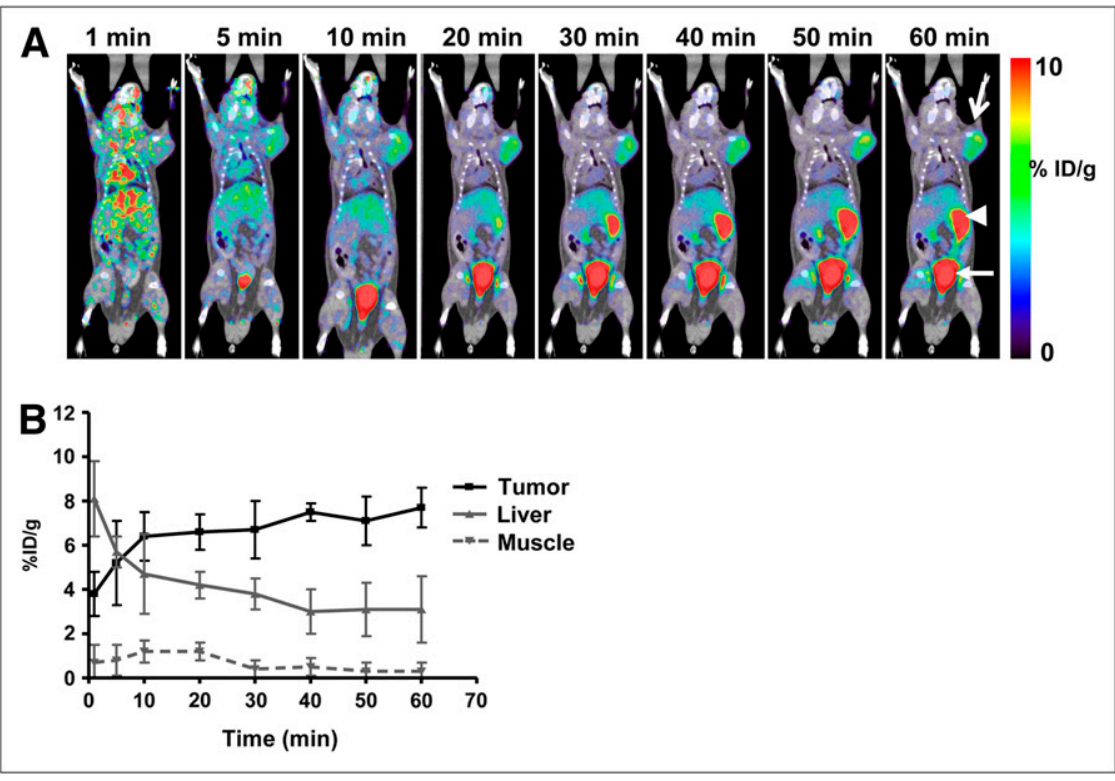

FIGURE 4. (A) Serial small-animal PET/ CT images from 1-h dynamic scan of mouse bearing DAbR1-expressing tumor on right shoulder (U-87-DAbR1 xenograft, open arrow; tracer excretion to small bowel, arrowhead; urinary bladder, closed arrow). (B) Corresponding time-activity curves for tumor, liver, and skeletal muscle (average and SD, $n=3$ ). 


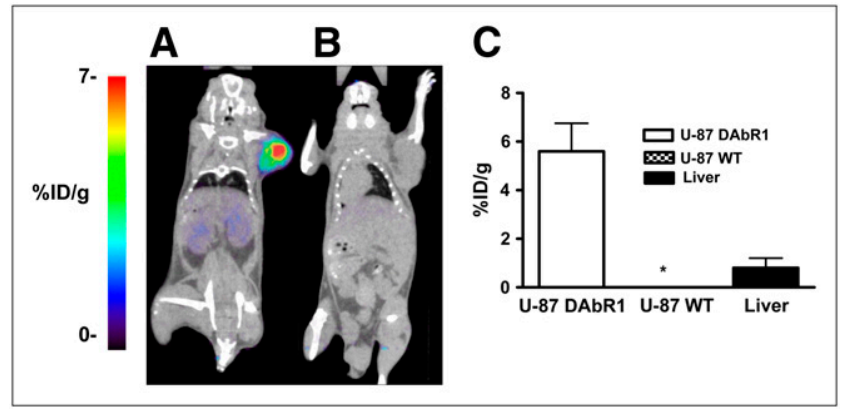

FIGURE 5. Small-animal PET/CT images of mice scanned $14 \mathrm{~h}$ after injection of ${ }^{86} \mathrm{Y}-\mathrm{AABD}$, with mouse bearing DAbR1positive U-87 tumor (A) and mouse bearing wild-type U-87 tumor (B). Radiotracer accumulation in wild-type tumors $(n=3)$ and DAbR1-expressing tumors $(n=3)$ is demonstrated, and radiotracer uptake in liver is shown for comparison (C). *Radiotracer uptake by wild-type U-87 tumors and muscle is less than $0.1 \%$ ID/g. WT $=$ wild type.

appear more favorable, enabling earlier imaging of tumors expressing the reporter gene.

In addition to reporter gene imaging, DAbR1-*Y-AABD could potentially be used for radiotherapy of malignant tumors after adenoviral gene transfer. Because *Y-AABD is rapidly cleared from the circulation and not accumulated in any normal tissue, the radiation exposure of normal tissues is expected to be small. In fact, the 2D12.5 antibody was initially developed for radioimmunotherapy with ${ }^{90} \mathrm{Y}$-DOTA complexes (36). Because ${ }^{90} \mathrm{Y}$ emits high-energy $\beta$-radiation with a maximum tissue penetration of almost $1 \mathrm{~cm}$, expression of the suicide gene by a fraction of the cancer cells within a tumor mass may be sufficient for achieving a therapeutic effect.

The following limitations of the study should be noted. We used ${ }^{86} \mathrm{Y}$ for PET to obtain proof of principle that the *YAABD-DabR1 represents a promising reporter gene-reporter probe combination. However, the physical characteristics of ${ }^{86} \mathrm{Y}$ limit its usefulness for PET. The positron abundance of ${ }^{86} \mathrm{Y}$ is only $33 \%$. Furthermore ${ }^{86} \mathrm{Y}$ emits $\gamma$-rays with energies up to $3,000 \mathrm{keV}$, which are partly emitted simultaneously with the positron, so that a considerable amount of $\gamma$-coincidences occurs (37). These characteristics limit image quality of ${ }^{86} \mathrm{Y}$ PET scans and make quantitative analysis of the PET signal challenging (37). AABD analogs can be labeled with other radionuclides more suitable for PET, such as ${ }^{64} \mathrm{Cu}$. The 2D12.5/G54C antibody binds a variety of DOTA radiometal complexes (36). Unfortunately, affinity is low for DOTA complexes with PET radionuclides such as ${ }^{64} \mathrm{Cu}$. U-87 cells expressing DAbR1 did not show significant binding of ${ }^{64} \mathrm{Cu}-$ AABD in vitro (data not shown). However, the crystal structure of the 2D12.5/G54C-DOTA complex indicates that DOTA can be modified at position 2 without affecting 2D12.5/G54C binding (38). A bifunctional DOTA complex consisting of two 2-(bromoacetamidobenzyl)-DOTA molecules joined by a 1,4-dithio-butane linker has been shown to bind to 2D12.5/G54C with high affinity in vivo $(39,40)$. Thus, ${ }^{89}$ Y-DOTA- ${ }^{64} \mathrm{Cu}$-DOTA or similar constructs could potentially be used for PET.
The DAbR1 reporter gene was generated from the mouse monoclonal antibody 2D12.5/G54C. For clinical studies, a humanized version of $2 \mathrm{D} 12.5$ could be used to generate other DOTA-binding reporter genes. The potential of immunogenicity for such reporter genes is lower than that for viral proteins, such as HSV1-tk. However, the fusion of the antibody fragment to the transmembrane domain of CD4 may generate a potential site for immune reactions. Future studies are necessary to study the immunogenicity of DAbR1.

\section{CONCLUSION}

This study shows the feasibility of using an antibody fragment with irreversible binding to AABD as a reporter gene for PET. The high and prolonged tumor uptake of AABD, the rapid excretion of AABD from all normal tissues, and the low potential for immunogenicity make DAbR1$\mathrm{AABD}$ a promising reporter gene-reporter probe combination for imaging transplanted cells and monitoring gene therapy.

\section{ACKNOWLEDGMENTS}

We thank Gerald Toy, Jenny Shu, Dean Campbell, and Martin Walter for their help with the cell culture and animal experiments. We also thank Waldemar Ladno, Antonia Luu, Judy Edwards, and Dr. David Stout for excellent technical assistance with animal imaging. This work was supported by the UCLA ICMIC (NCI P50 CA086306) and the UCLA IMED (DE-FC03-87E60615) grants, and NIH Research grant CA016861.

\section{REFERENCES}

1. Topol EJ. Current status and future prospects for acute myocardial infarction therapy. Circulation. 2003;108:III6-III13.

2. Burt RK, Loh Y, Pearce W, et al. Clinical applications of blood-derived and marrow-derived stem cells for nonmalignant diseases. JAMA. 2008;299:925-936.

3. Morgan RA, Dudley ME, Wunderlich JR, et al. Cancer regression in patients after transfer of genetically engineered lymphocytes. Science. 2006;314:126-129.

4. Shapiro AM, Ricordi C, Hering BJ, et al. International trial of the Edmonton protocol for islet transplantation. N Engl J Med. 2006;355:1318-1330.

5. Walter BL, Vitek JL. Surgical treatment for Parkinson's disease. Lancet Neurol. 2004;3:719-728.

6. Peschanski M, Bachoud-Levi AC, Hantraye P. Integrating fetal neural transplants into a therapeutic strategy: the example of Huntington's disease. Brain. 2004;127:1219-1228.

7. Tjuvajev JG, Stockhammer G, Desai R, et al. Imaging the expression of transfected genes in vivo. Cancer Res. 1995;55:6126-6132.

8. Blasberg RG, Tjuvajev JG. Molecular-genetic imaging: current and future perspectives. J Clin Invest. 2003;111:1620-1629.

9. Gambhir SS, Bauer E, Black ME, et al. A mutant herpes simplex virus type 1 thymidine kinase reporter gene shows improved sensitivity for imaging reporter gene expression with positron emission tomography. Proc Natl Acad Sci USA. 2000;97:2785-2790.

10. Riddell SR, Elliott M, Lewinsohn DA, et al. T-cell mediated rejection of genemodified HIV-specific cytotoxic T lymphocytes in HIV-infected patients. Nat Med. 1996;2:216-223.

11. Shu CJ, Guo S, Kim YJ, et al. Visualization of a primary anti-tumor immune response by positron emission tomography. Proc Natl Acad Sci USA. 2005; 102:17412-17417.

12. Spitzweg C, Zhang S, Bergert ER, et al. Prostate-specific antigen (PSA) promoter-driven androgen-inducible expression of sodium iodide symporter in prostate cancer cell lines. Cancer Res. 1999;59:2136-2141. 
13. Haberkorn U, Henze M, Altmann A, et al. Transfer of the human NaI symporter gene enhances iodide uptake in hepatoma cells. J Nucl Med. 2001;42:317-325.

14. Altmann A, Kissel M, Zitzmann S, et al. Increased MIBG uptake after transfer of the human norepinephrine transporter gene in rat hepatoma. J Nucl Med. 2003; 44:973-980.

15. Anton M, Wagner B, Haubner R, et al. Use of the norepinephrine transporter as a reporter gene for non-invasive imaging of genetically modified cells. J Gene Med. 2004;6:119-126.

16. Zinn KR, Chaudhuri TR. The type 2 human somatostatin receptor as a platform for reporter gene imaging. Eur J Nucl Med Mol Imaging. 2002;29:388-399.

17. MacLaren DC, Gambhir SS, Satyamurthy N, et al. Repetitive, non-invasive imaging of the dopamine $\mathrm{D}_{2}$ receptor as a reporter gene in living animals. Gene Ther. 1999;6:785-791.

18. Northrop JP, Bednarski M, Barbieri SO, et al. Cell surface expression of single chain antibodies with applications to imaging of gene expression in vivo. Eur J Nucl Med Mol Imaging. 2003;30:1292-1298.

19. Roffler SR, Wang HE, Yu HM, et al. A membrane antibody receptor for noninvasive imaging of gene expression. Gene Ther. 2006;13:412-420.

20. Meyer DL, Fineman M, Unger BW, Frincke JM. Kinetics of the dissociation of indium-(p-substituted-benzyl)ethylenediaminetetraacetic acid hapten analogues from the monoclonal anti-hapten antibody CHA255. Bioconjug Chem. 1990;1:278-284.

21. Corneillie TM, Whetstone PA, Meares CF. Irreversibly binding anti-metal chelate antibodies: artificial receptors for pretargeting. J Inorg Biochem. 2006; 100:882-890.

22. Corneillie TM, Whetstone PA, Lee KC, Wong JP, Meares CF. Converting weak binders into infinite binders. Bioconjug Chem. 2004;15:1389-1391.

23. Jensen M, Tan G, Forman S, Wu AM, Raubitschek A. CD20 is a molecular target for scFvFc:zeta receptor redirected $\mathrm{T}$ cells: implications for cellular immunotherapy of CD20+ malignancy. Biol Blood Marrow Transplant. 1998;4:75-83.

24. Corneillie TM, Lee KC, Whetstone PA, Wong JP, Meares CF. Irreversible engineering of the multielement-binding antibody 2D12.5 and its complementary ligands. Bioconjug Chem. 2004;15:1392-1402.

25. Yoo J, Tang L, Perkins TA, et al. Preparation of high specific activity ${ }^{86} \mathrm{Y}$ using a small biomedical cyclotron. Nucl Med Biol. 2005;32:891-897.

26. Tai YC, Ruangma A, Rowland D, et al. Performance evaluation of the microPET focus: a third-generation microPET scanner dedicated to animal imaging. $\mathrm{J} \mathrm{Nucl}$ Med. 2005;46:455-463.

27. Chow P, Stout D, Komisopoulou E, Chatziioannou A. A method of image registration for small animal, multi-modality imaging. Phys Med Biol. 2006; $51: 379-390$
28. Loening AM, Gambhir SS. AMIDE: a free software tool for multimodality medical image analysis. Mol Imaging. 2003;2:131-137.

29. Min JJ, Iyer M, Gambhir SS. Comparison of $\left[{ }^{18} \mathrm{~F}\right] \mathrm{FHBG}$ and $\left[{ }^{14} \mathrm{C}\right] \mathrm{FIAU}$ for imaging of HSV1-tk reporter gene expression: adenoviral infection vs stable transfection. Eur J Nucl Med Mol Imaging. 2003;30:1547-1560.

30. Yang H, Berger F, Tran C, Gambhir SS, Sawyers CL. MicroPET imaging of prostate cancer in LNCAP-SR39TK-GFP mouse xenografts. Prostate. 2003; 55:39-47.

31. Ray P, Wu AM, Gambhir SS. Optical bioluminescence and positron emission tomography imaging of a novel fusion reporter gene in tumor xenografts of living mice. Cancer Res. 2003;63:1160-1165.

32. Schipper ML, Riese CG, Seitz S, et al. Efficacy of ${ }^{99 \mathrm{~m}} \mathrm{Tc}$ pertechnetate and ${ }^{131} \mathrm{I}$ radioisotope therapy in sodium/iodide symporter (NIS)-expressing neuroendocrine tumors in vivo. Eur J Nucl Med Mol Imaging. 2007;34:638-650.

33. Tjuvajev JG, Doubrovin M, Akhurst T, et al. Comparison of radiolabeled nucleoside probes (FIAU, FHBG, and FHPG) for PET imaging of HSV1-tk gene expression. J Nucl Med. 2002;43:1072-1083.

34. Chin FT, Namavari M, Levi J, et al. Semiautomated radiosynthesis and biological evaluation of $\left[{ }^{18} \mathrm{~F}\right] \mathrm{FEAU}$ : a novel PET imaging agent for HSV1-tk/ sr39tk reporter gene expression. Mol Imaging Biol. 2008;10:82-91.

35. Alauddin MM, Shahinian A, Gordon EM, Bading JR, Conti PS. Preclinical evaluation of the penciclovir analog 9-(4-[18F]fluoro-3-hydroxymethylbutyl)guanine for in vivo measurement of suicide gene expression with PET. $J$ Nucl Med. 2001;42:1682-1690.

36. Corneillie TM, Whetstone PA, Fisher AJ, Meares CF. A rare earth-DOTAbinding antibody: probe properties and binding affinity across the lanthanide series. J Am Chem Soc. 2003;125:3436-3437.

37. Herzog H, Tellmann L, Scholten B, Coenen HH, Qaim SM. PET imaging problems with the non-standard positron emitters yttrium-86 and iodine-124. $Q J$ Nucl Med Mol Imaging. 2008;52:159-165.

38. Corneillie TM, Fisher AJ, Meares CF. Crystal structures of two complexes of the rare-earth-DOTA-binding antibody 2D12.5: ligand generality from a chiral system. J Am Chem Soc. 2003;125:15039-15048.

39. Goodwin DA, Meares CF, Watanabe N, et al. Pharmacokinetics of pretargeted monoclonal antibody 2D12.5 and ${ }^{88}$ Y-Janus-2-(p-nitrobenzyl)-1,4,7,10tetraazacyclododecanetetraacetic acid (DOTA) in BALB/c mice with KHJJ mouse adenocarcinoma: a model for ${ }^{90} \mathrm{Y}$ radioimmunotherapy. Cancer Res. 1994; 54:5937-5946.

40. Lubic SP, Goodwin DA, Meares CF, Song C, Osen M, Hays M. Biodistribution and dosimetry of pretargeted monoclonal antibody 2D12.5 and Y-Janus-DOTA in BALB/c mice with KHJJ mouse adenocarcinoma. J Nucl Med. 2001;42:670-678. 